\title{
BIOMECHANICS AND HISTOLOGICAL ANALYSIS IN RABBIT FLEXOR TENDONS REPAIRED USING THREE SUTURE TECHNIQUES (FOUR AND SIX STRANDS) WITH EARLY ACTIVE MOBILIZATION
}

Antônio Lourenço Severo', Rodrigo Arenhart², Daniela Silveira ${ }^{3}$, Aluísio Otávio Vargas Ávila ${ }^{4}$, Francisco José Berral ${ }^{5}$, Marcelo Barreto Lemos $^{6}$, Paulo César Faiad Piluski ${ }^{6}$, Osvandré Luís Canfield Lech ${ }^{7}$, Walter Yoshinori Fukushima ${ }^{8}$

\begin{abstract}
Objective: Analyzing suture time, biomechanics (deformity between the stumps) and the histology of three groups of tendinous surgical repair: Brazil-2 (4-strands) which the end knot (core) is located outside the tendon, Indiana (4-strands) and Tsai (6-strands) with sutures technique which the end knot (core) is inner of the tendon, associated with early active mobilization. Methods: The right calcaneal tendons (plantar flexor of the hind paw) of 36 rabbits of the New Zealand breed (Oryctolagus cuniculus) were used in the analysis. This sample presents similar size to human flexor tendon that has approximately $4.5 \mathrm{~mm}$ (varying from $2 \mathrm{~mm}$ ). The selected sample showed the same mass $(2.5$ to $3 \mathrm{~kg}$ ) and were male or female adults (from 8 $1 / 2$ months). For the flexor tendons of the hind paws, sterile and driven techniques were used in accordance to the Committee on Animal Research and Ethics (CETEA) of the University of the State of Santa Catarina (UDESC), municipality of Lages, in Brazil (protocol \# 1.33.09). Results: In the
\end{abstract}

biomechanical analysis (deformity) carried out between tendinous stumps, there was no statistically significant difference $(p>0.01)$. There was no statistical difference in relation to surgical time in all three suture techniques with a mean of 6.0 minutes for Tsai (6- strands), 5.7 minutes for Indiana (4-strands) and 5.6 minutes for Brazil (4-strands) ( $p>0.01)$. With the early active mobility, there was qualitative and quantitative evidence of thickening of collagen in $38.9 \%$ on the $15^{\text {th }}$ day and in $66.7 \%$ on the $30^{\text {th }}$ day, making the biological tissue stronger and more resistant $(\mathrm{p}=0.095)$. Conclusion: This study demonstrated that there was no histological difference between the results achieved with an inside or outside end knot with respect to the repaired tendon and the number of strands did not affect healing, vascularization or sliding of the tendon in the osteofibrous tunnel, which are associated with early active mobility, with the repair techniques applied.

Keywords - Suture; Calcaneal Tendon; Wound Healing

\section{INTRODUCTION}

The current flexor tendon repair techniques consist of multiple sutures, with strands passing through and going around the circumference of the tendon. These sutures are designed to maintain the stress produced by active mobility, especially when it starts early on. Active mobility produces tension and action, provi- ding advantages over passive mobility, including: improved nutrition, diminished adherence, facilitation of healing and increased strength at the repair site, without occurrences of re-rupture ${ }^{(1-7)}$.

Protocols for rehabilitation treatment subsequent to operations involving sutures on hand flexor tendons in which immediate passive mobilization is recommended originated in the 1960s, 1970s and 1980s.

\footnotetext{
1. Doctor, Master's Degree in Biomechanics of the Upper Limb Surgery Center of the Instituto de Ortopedia e Traumatologia (IOT) - Passo Fundo, RS

2. Professor and Master in Biomechanics at the Universidade Regional Integrada (URI) - Erechim - RS, Brazil.

3. Professor and Master in Clinical Pathology at the Universidade de Passo Fundo (UPF) - Passo Fundo, RS, Brazil.

4. Professor and Doctor at the Biomechanics Laboratory of the Universidade Estadual de Santa Catarina (UDESC) - Florianópolis, SC, Brazil.

5. Professor and Doctor, Director of the Sports and Information Technology Department of the Universidade Pablo de Olavide (UPO) - Sevilha, Spain.

6. Doctor of Upper Limb Surgery Center of the IOT - Passo Fundo, RS.

7. Head of Medical Residency of the IOT - Passo Fundo, RS, Brazil.

8. Professor and Doctor of the Faculty of medicine, ABC (FMABC) - Santo André, SP, Brazil.

Work carried out at the Experimental Surgery Laboraotry of the Instituto de Ortopedia e Traumatologia de Passo Fundo (IOT-RS).

Correspondence: Rua Uruguai, 2050 - 99010-112 - Passo fundo, RS. E-mail: al.severo@terra.com.br

Received for publication: 02/21/2010, accepted for publication: 07/12/2011
}

The authors declare that there was no conflict of interest in conducting this work 
However, in the 1990s and 2000s, several clinical studies recommended early active mobilization, with good results and low re-rupture rates ${ }^{(8-13)}$.

The present paper was based on an experimental study on rabbits. In the literature, there are studies with a variety of investigation protocols in which models were applied to cadavers and to animals such as pigs, dogs and rabbits, using different suture materials (nylon, mersilene, Ethibond, Dacron and steel) ${ }^{(14-22)}$.

Despite the diversity of experimental investigation on animals, the greatest quantity of research has been on cadavers. However, the great limitation of biomechanical tests on hand models using human cadavers is that information is obtained only on the immediate post-repair state: the healing conditions cannot be simulated. Because ruptures, deformities (separations) and adherences usually occur days or weeks after surgery, these effects from repairs can only be simulated and extrapolated from in vivo animal models ${ }^{(3)}$.

The present study was based on Resolution 714 of the Regional Veterinary Medicine Council of Santa Catarina, Brazil, and on Federal Law No. 9605, of February 1998, regarding use of animals in experimental studies. The aim of this study was to analyze the biomechanics (deformity of tendon stumps), time taken to perform the repair and histology of three suture groups: Brazil-2 (4-strand) ${ }^{(23)}$, with the final knot of the central suture located outside of the tendon repair; Indiana (4-strand) ${ }^{(24)}$; and Tsai (6-strand) ${ }^{(25)}$, with the final knots of the central suture located inside the tendon repair. The calcaneal tendons (plantar flexors of the hind legs) of rabbits were used for this experimental study, in association with early active mobilization.

\section{MATERIALS AND METHODS}

\section{Experimental design}

The sample was non-random, using arbitrage, because of the closeness to human tissue of the characteristics and properties of the animal model selected. A total of 36 adult male or female New Zealand rabbits (Oryctolagus cuniculus), aged $81 / 2$ months and weighing 2.5 to $3 \mathrm{~kg}$, were selected. The right calcaneal tendon (plantar flexor of the hind leg) was chosen for the analysis. This is of similar thickness to the human flexor tendon, with a diameter of approximately 4.5 $\mathrm{mm}$ (varying $2 \mathrm{~mm}$ upwards and downwards). Sterile techniques were used on these tendons, conducted in accordance with the requirements of the Ethics Committee for Animal Experimentation (CETEA) of the State University of Santa Catarina (UDESC), in the city of Lages, Brazil (protocol no. 1.33.09). The provider of these animals fulfilled adequate care requirements in relation to these animals' rearing and health, and held a license for this (number 0581039548), authorized and supervised by the Ministry of Agriculture in Rio Grande do Sul, Brazil.

The 36 tendons were divided into three suture groups: Brazil-2 (4-strand) ${ }^{(23)}$, with a central suture and a final knot located outside of the tendon repair; Indiana (4-strand) ${ }^{(24)}$; and Tsai (6-strand) ${ }^{(25)}$, with central sutures in which the final knots were located inside the tendon repair. In order to analyze the histological and biomechanical characteristics (deformity of the tendon stumps) of each experimental group, the rabbits were sacrificed: six animals on the $15^{\text {th }}$ day after the operation and six on the $30^{\text {th }}$ day (Table 1).

Table 1 - Sample distribution in each investigation group (Source: Experimental Surgery Laboratory, Institute of Orthopedics and Traumatology, Passo Fundo, RS, Brazil).

\begin{tabular}{|c|c|c|c|c|}
\hline \multicolumn{4}{|c|}{ Suture techniques } & \multirow[b]{2}{*}{ Total } \\
\hline Day & GI Brazil-2 (R) & GII Indiana (R) & GIII Tsai (R) & \\
\hline $15^{*}$ & 6 tendons & 6 tendons & 6 tendons & \\
\hline $30^{*}$ & 6 tendons & 6 tendons & 6 tendons & 36 \\
\hline
\end{tabular}

R: right hind leg.

*: Day on which the rabbits were sacrificed in order to conduct histological analysis and measurements on the deformity (separation) of the tendon stumps.

\section{Data-gathering procedures:}

All the procedures were performed in a sterile manner that resembled the technique described by Kusano et $\mathrm{al}^{(14)}$. Each animal was anesthetized by means of intramuscular injection of ketamine hydrochloride (50 $\mathrm{mg} / \mathrm{kg}$ ) and local complementation with $2 \%$ lidocaine hydrochloride, without a vasoconstrictor. This was always done on the external face of the right hind leg. Antibiotic consisting of cefazolin (300 mg) was also added as prophylaxis to avoid infections. A longitudinal incision of $6 \mathrm{~cm}$ was then made proximally to distally, from the knee to the ankle. The retinaculum of the flexors and the osteofibrous tunnel were opened longitudinally to expose the calcaneal tendon (plantar flexor of the hind leg). The tendon was then totally sectioned transversally and was repaired using one of the three suture techniques: 4-strand (Brazil-2), 4-strand (Indiana) or 6-strand (Tsai) ${ }^{(25)}$. All the central sutures were made using nylon 4.0 and the sutures around the tendon were made using nylon 5.0. After 
the operation, immobilization consisting of a plastercast boot extending from the knee to the foot (while leaving the toes free) was applied such that the ankle was restrained at $90^{\circ}$. This immobilization protected the operative wound on the leg, given that these rodents are difficult to control. The immobilization was not removed, nor was it replaced if the animal happened to gnaw it off or lose it. The animals were put in cages of dimensions $80 \times 60 \times 60 \mathrm{~cm}$, with a central divider so that two rabbits could use each cage. They were able to move around, while conflict between them was avoided. Distilled water and food suitable for rabbits were provided (Figures 1 and 2).

\section{Deformity between the tendon stumps (biomechanical test)}

The animals were allowed to walk around half of the cage $(80 \times 60 \times 60 \mathrm{~cm})$ with the plaster-cast immobilization protecting the wound, starting immediately after the surgery. This was named early active movement. They could do this freely, bearing their own body weight (mean of 2.5 to $3 \mathrm{~kg}$ ). The animals were sacrificed either on the $15^{\text {th }}$ or on the $30^{\text {th }}$ day after tendon suturing, in order to measure the separation between the stumps (deformity), using a millimeter grid under a 40x microscope.

\section{Time taken to do suturing}

The three suture techniques on the flexor tendons of the hind legs (calcaneal tendons) of the rabbits were performed by three senior surgeons, and the time taken to do the suturing was analyzed.

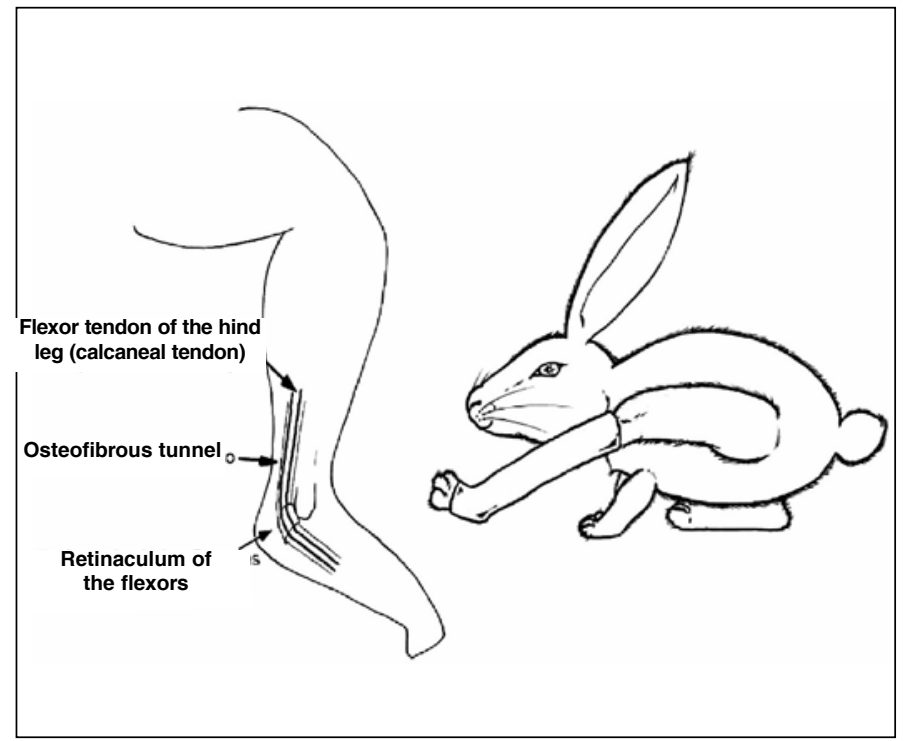

Figure 1 - Procedure for data gathering: schematic diagram of rabbit anatomy, with immobilization of the hind leg to protect the wound ${ }^{(14)}$.

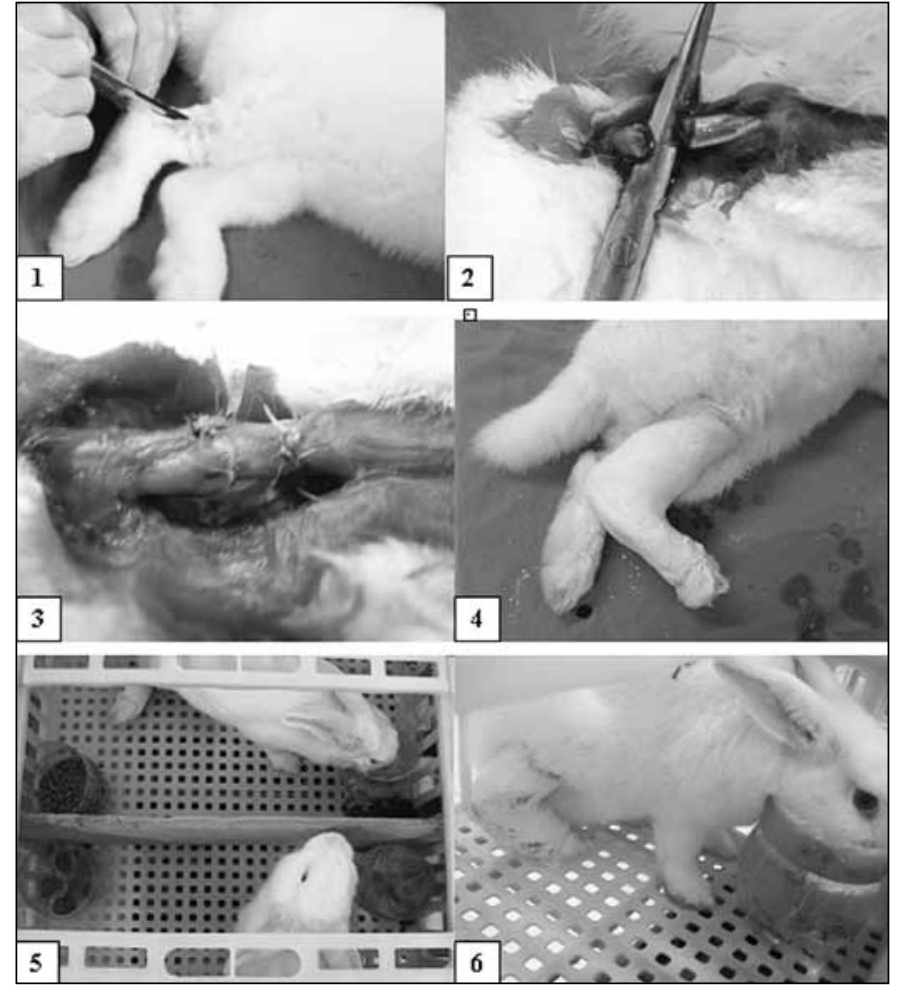

Figure 2 - 1. Incision in the right hind leg; 2 . Calcaneal tendon (flexor tendon of the hind leg) sectioned; 3. Performing the tendon repair; 4 . Immobilization with plaster cast to protect the wound; 5 . Cage of dimensions $80 \times 60 \times 60 \mathrm{~cm}$ with a dividing panel; 6. Rabbit drinking and eating two hours after the procedure.

(Source: Experimental Surgery Laboratory, Institute of Orthopedics and Traumatology, Passo Fundo, RS, Brazil).

\section{Histological analysis}

Six rabbits from each experimental group were sacrificed on the $15^{\text {th }}$ day and six on the $30^{\text {th }}$ day, so that the tendons could be histologically analyzed (Table 1). For this histological analysis, the repaired tendon unit was embedded in paraffin and sections of thickness 5 microns $(5 \mathrm{u})$ were made longitudinally and transversally. The slides were viewed at magnifications of 40x, 100x and 200x and were stained using two preparations: 1) Gomori trichrome, which shows collagen fibers in green and fibroblasts in red with dark or blue nuclei; and 2) hematoxylin-eosin (HE), to observe the nuclei and cytoplasm better. These histological parameters or indicators were used to demonstrate the healing behavior of the tendon, with early active mobility, and the scarring effect of the final (central) knot with the osteofibrous tunnel. The knot was either inside or outside of the tendon, according to the suture technique used.

\section{Sacrifice}

After the animal had been sedated and hypnotized using midazolam (15 mg), inhaled halothane was ap- 
plied, which resulted in cardiorespiratory arrest and death. The tendons were then removed for histological and biometric analysis and were immediately immersed in $10 \%$ buffered formol solution, in individually identified flasks. The time between death and tendon extraction did not exceed 36 hours, and during this period, the cadavers were kept in a cold-store chamber at $4^{\circ} \mathrm{C}$. Afterwards, the carcasses were disposed of by burial in wooden boxes on a private smallholding.

\section{Data processing:}

The statistical investigation was performed using the SPSS for Windows software, version 10.0. The Levene homogeneity distribution test was applied so that analysis of variance (ANOVA) with 1\% significance could be used for analysis between the three suture groups. To correlate the suture technique with the time elapsed after surgery and the histological characteristics, Pearson's chi-square test was chosen.

\section{Suturing methods:}

The material used was nylon 4.0 for the central suture (nucleus) and nylon 5.0 for the continual peripheral suture (around the tendon)*

Brazil-2 (4-strand) suture ${ }^{* *}$ : the final knot of the central suture was located outside of the tendon repair (Figure 3) $^{(23)}$.

Indiana or Strickland (4-strand) suture $^{* * *}$ : both knots of the central (final) suture were located inside the tendon repair (Figure 4$)^{(24)}$.

Lim and Tsai ${ }^{(25)}$ (6-strand) suture ${ }^{* *}$ : both knots of the central (final) suture were located inside the tendon repair. Two "loop" needles were used (Figure 5).

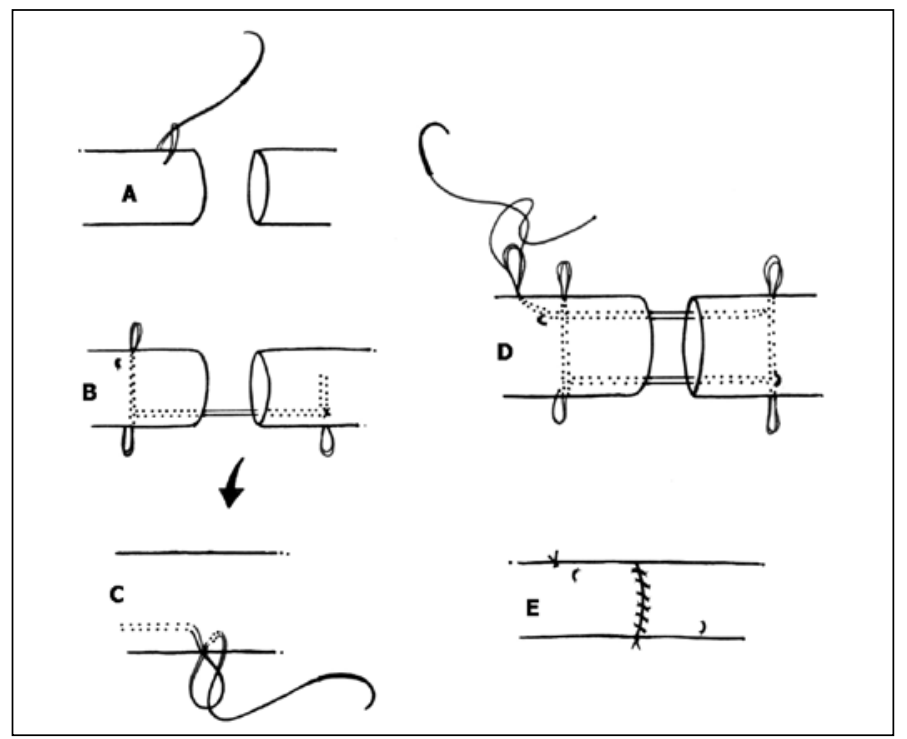

Figure 3 - Brazil(23) technique.

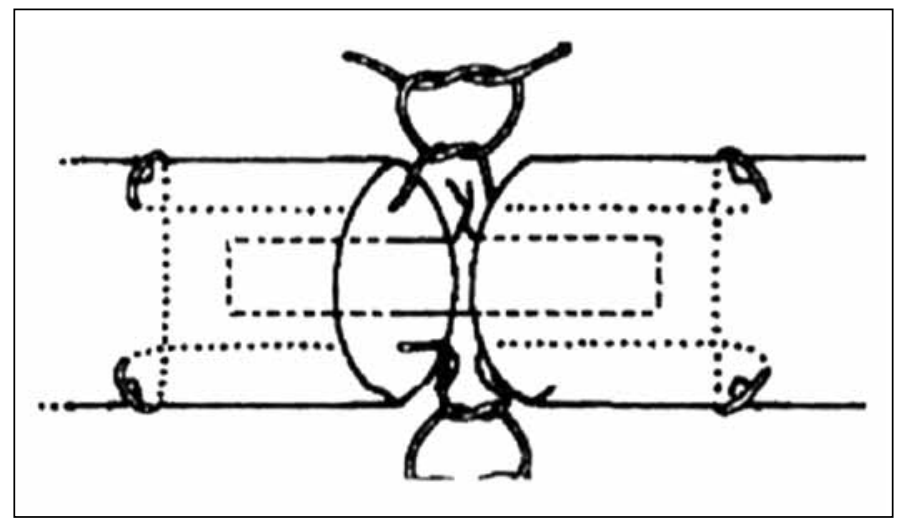

Figura 4 - Técnica de Indiana ${ }^{(24)}$.

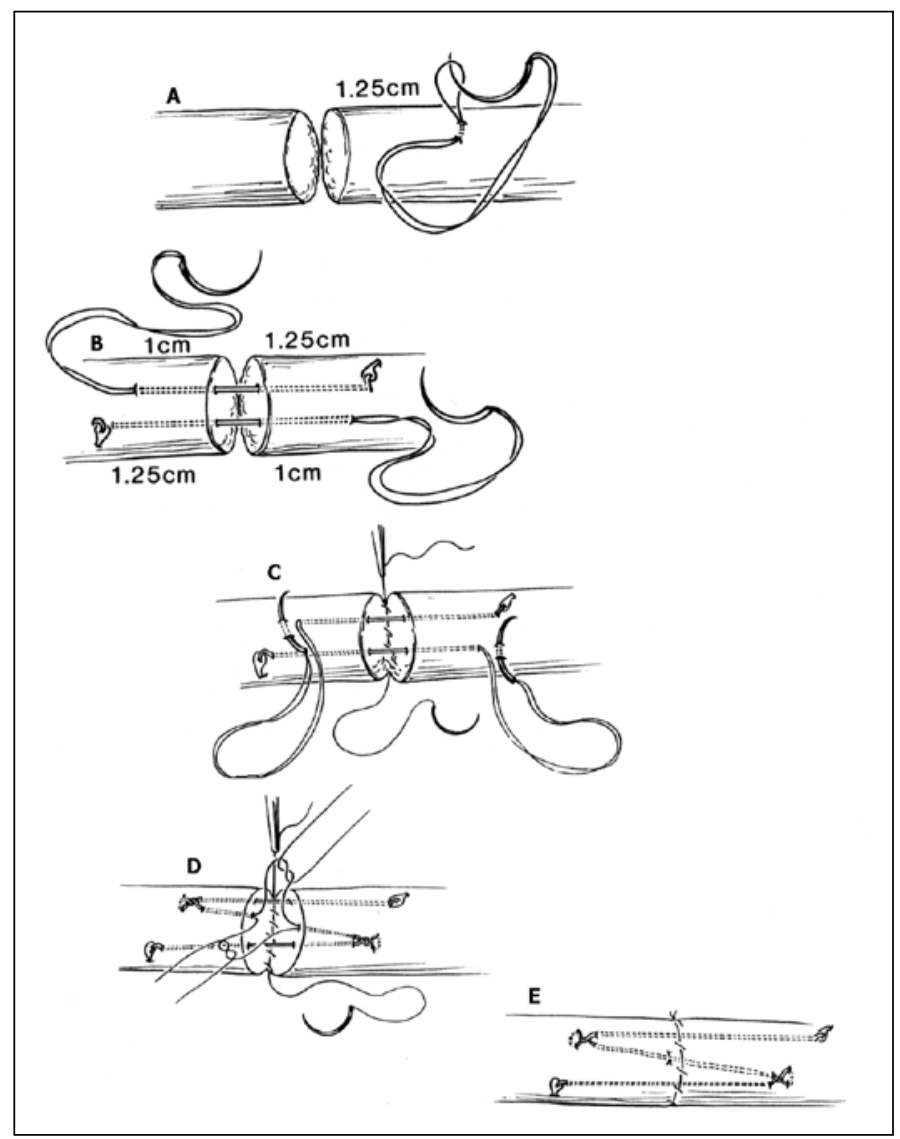

Figure 5 - Tsai technique (Lim and Tsai, 1996) ${ }^{25}$.

\section{RESULTS}

Deformity between the tendon stumps (biomechanical test): In this investigation, the deformity (separation) between the tendon stumps was measured in millimeters using 40x magnification under a microscope. Using the Brazil-2 (4-strand) repair technique on the $15^{\text {th }}$ day, there were two sutures with a separation of $25 \mathrm{~mm}$ between the stumps, with only a few thin collagen fibers and a large amount of amorphous cellular tissue. Using the Indiana (4-strand) 
repair technique on the $15^{\text {th }}$ day, there was one suture with a separation of $25 \mathrm{~mm}$ between the stumps and also with only a few thin collagen fibers and a large amount of amorphous cellular tissue. In other words, tissue with tendon characteristics had not formed and, thus, it could be considered that technical rupture had occurred. Using the Tsai (6-strand) repair technique on the $15^{\text {th }}$ day, the maximum separation was $17 \mathrm{~mm}$, with thick collagen fibers, thus demonstrating strong biological tissue structuring. Nevertheless, there was no statistically significant difference (ANOVA; $\mathrm{p}>$ 0.01) (Figure 6). It should also be taken into account that the rabbits were allowed to start to walk around immediately after the surgery, inside half of a cage of dimensions $80 \times 60 \times 60 \mathrm{~cm}$, with plaster-cast immobilization to protect the wound, i.e. with early active movement. In freely moving around, the animals were bearing their own body weight (mean of 2.5 to $3 \mathrm{~kg}$ ).

\section{Time taken to do suturing:}

The three suture techniques on the flexor tendons of the hind legs (calcaneal tendons) of the rabbits were performed by three senior surgeons, as mentioned earlier. The time taken to do the procedure was analyzed and there were no statistically significant differences (ANOVA; $p>0.01$ ) (Figure 7).

\section{Histological analysis:}

Thickening of the collagen fibers was seen qualitatively and quantitatively in seven $(38.9 \%)$ of the rabbits by the $15^{\text {th }}$ day and in $12(66.7 \%)$ by the $30^{\text {th }}$ day $(\mathrm{p}=$ 0.095), such that stronger and more resistant biological tissue was formed. It was observed that between the $15^{\text {th }}$ and the $30^{\text {th }}$ days, the fibers started to accommodate to a horizontal orientation along the axis of the repaired tendon, thus maturing the healing process (Figures 8, 9 and 10).

Among the rabbits that received the Brazil-2 (4-strand) suture technique, two on the $15^{\text {th }}$ day $(33.3 \%)$ and four on the $30^{\text {th }}$ day $(66.7 \%)$ predominantly presented thick fibers in their tendons $(p=0.248)$. Among the rabbits that received the Indiana (4-strand) suture technique, one on the $15^{\text {th }}$ day $(16.7 \%)$ and four on the $30^{\text {th }}$ day $(66.7 \%)$ predominantly presented thick fibers in their tendons $(p=0.079)$. Among the rabbits that received the Tsai (6-strand) suture technique, four on the $15^{\text {th }}$ day $(66.7 \%)$ and four on the $30^{\text {th }}$ day $(66.7 \%)$ predominantly presented thick fibers in their tendons $(\mathrm{p}=1.000)$ (Table 2 and Figure 11).

No presence of collagen fiber callus was observed,

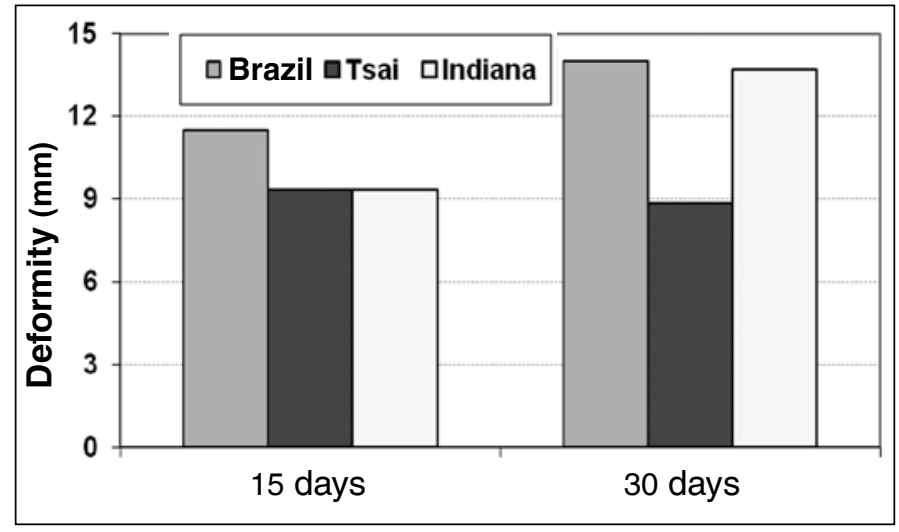

Figure 6 - Deformity (separation between the tendon stumps, measured in millimeters on the $15^{\text {th }}$ and $30^{\text {th }}$ days after surgery. There was no statistically significant difference (ANOVA; $p>0.01$ ). (Source: Experimental Surgery Laboratory, Institute of Orthopedics and Traumatology, Passo Fundo, RS, Brazil).

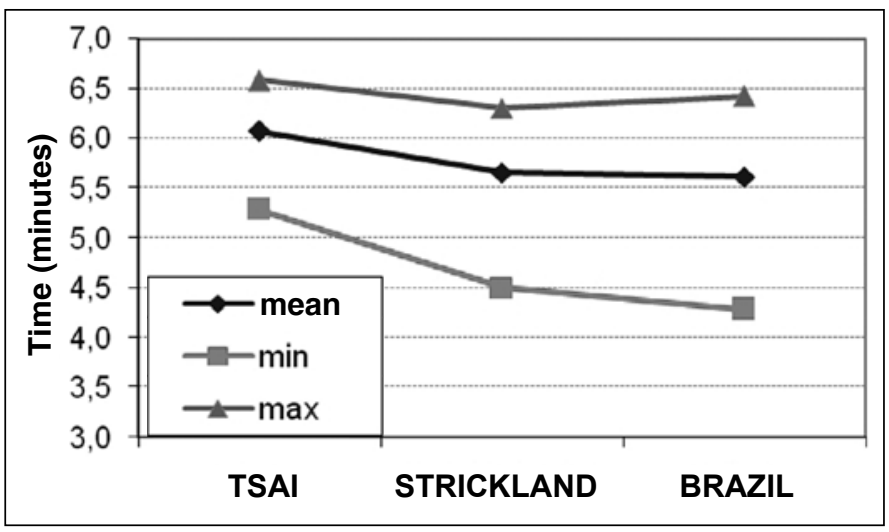

Figure 7 - Analysis on time taken to perform sutures. There was no statistically significant difference between the techniques, with means of: 6.0 minutes for Tsai (six-strand), 5.7 minutes for Indiana (fourstrand) and 5.6 minutes for Brazil (four-strand), (ANOVA; $p>0.01$ ). (Source: Experimental Surgery Laboratory, Institute of Orthopedics and Traumatology, Passo Fundo, RS, Brazil).

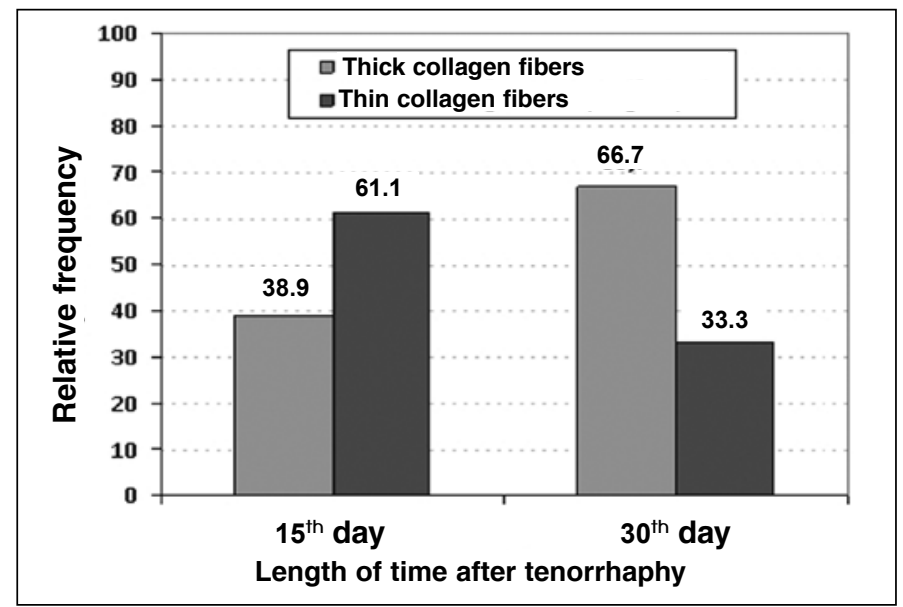

Figure 8 - General demonstration of the relative frequency of thickening of collagen fibers: $38.9 \%$ by the $15^{\text {th }}$ day and $66.7 \%$ by the $30^{\text {th }}$ day, thus producing stronger and more resistant biological tissue $(p=0.095)$.

(Source: Experimental Surgery Laboratory, Institute of Orthopedics and Traumatology, Passo Fundo, RS, Brazil). 


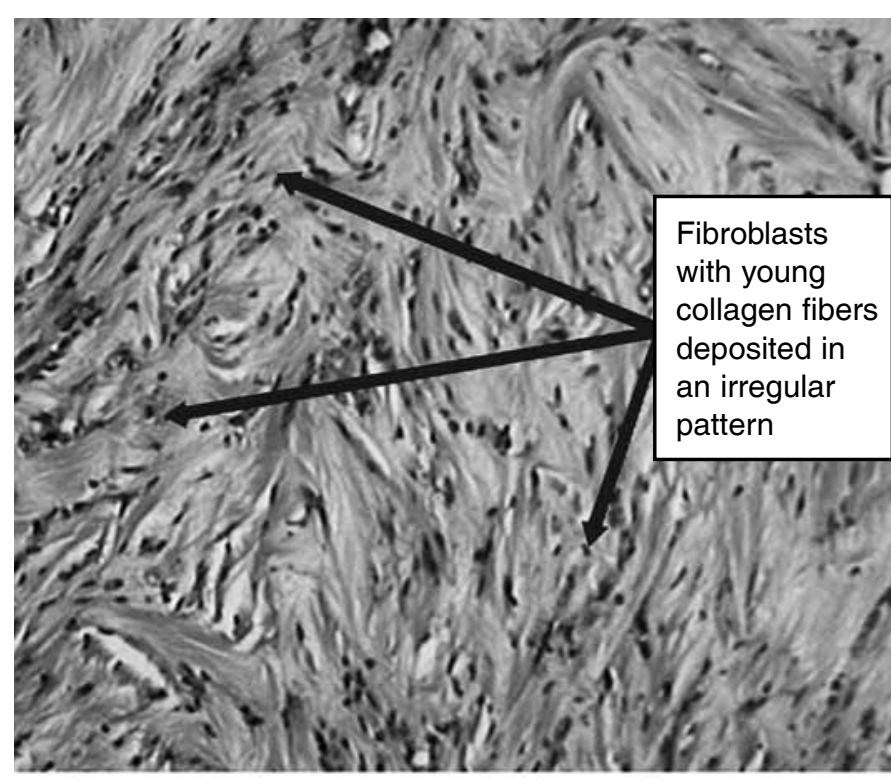

Figure 9 - Tsai technique (6-strand) on the $15^{\text {th }}$ day, at the start of healing, with immature collagen fibers (100x).

(Source: Experimental Surgery Laboratory, Institute of Orthopedics and Traumatology, Passo Fundo, RS, Brazil).

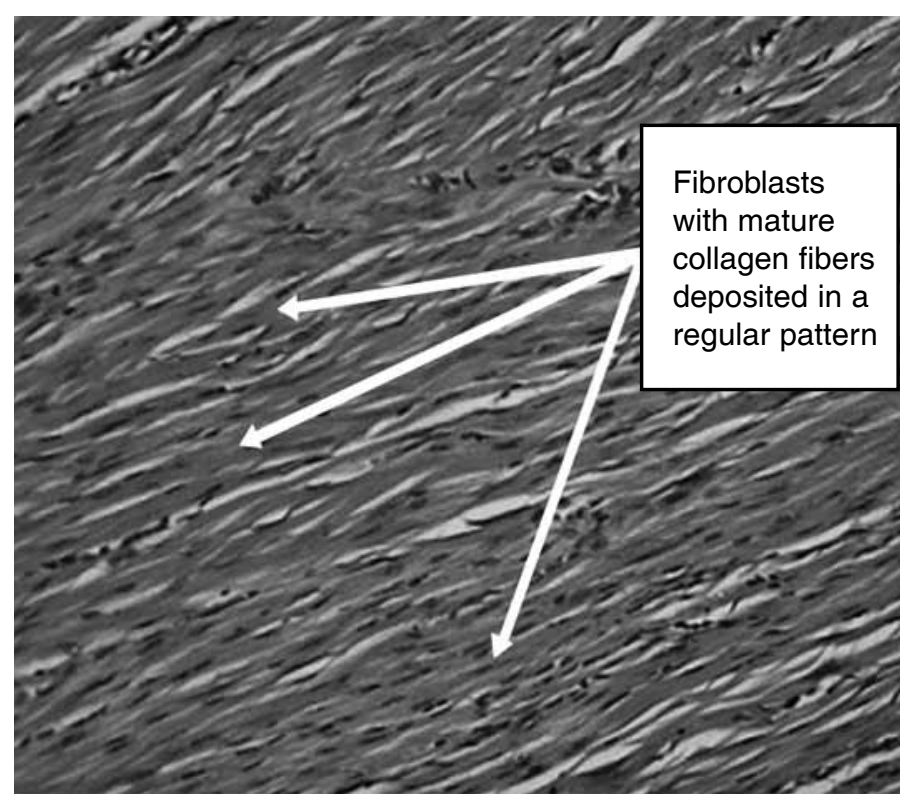

Figure 10 - Tsai technique (6-strand) on the $30^{\text {th }}$ day, showing the positions of the mature collagen fibers: aligned with the tendon axis, i.e. ideal healing $(100 x)$.

(Source: Experimental Surgery Laboratory, Institute of Orthopedics and Traumatology, Passo Fundo, RS, Brazil).

Table 2 - Absolute and relative frequencies of thick collagen fibers on the $15^{\text {th }}$ and $30^{\text {th }}$ days, after applying the different surgical techniques.

\begin{tabular}{c|c|c|c}
\hline \multirow{2}{*}{ Thick fibers } & \multicolumn{3}{|c}{ Suture technique } \\
\hline Day & Brazil-2 & Indiana & Tsai \\
\hline $15^{\text {th }}$ & $2(33.3 \%)$ & $1(16.7 \%)$ & $4(66.7 \%)$ \\
\hline $30^{\text {th }}$ & $4(66.7 \%)$ & $4(66.7 \%)$ & $4(66.7 \%)$ \\
\hline
\end{tabular}

(Source: Experimental Surgery Laboratory, Institute of Orthopedics and Traumatology, Passo Fundo, RS, Brazil).

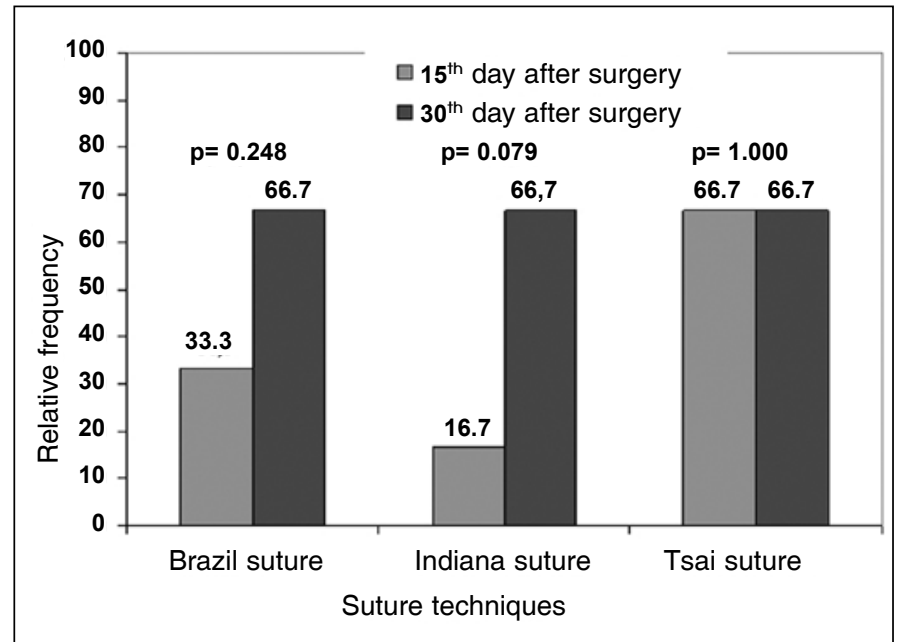

Figure 11 - Relative frequencies of thick fibers on the $15^{\text {th }}$ and $30^{\text {th }}$ days after the surgical procedure, using the three different suture techniques.

(Source: Experimental Surgery Laboratory, Institute of Orthopedics and Traumatology, Passo Fundo, RS, Brazil).

either qualitatively or quantitatively, in 33 (91.7\%) of the cases analyzed histologically. Thus, this finding contests the notion that excessive friction in relation to the osteofibrous tunnel would be produced by the final central knot of the tendon when it is outside of the repaired tendon, thereby impairing the capacity of the tunnel to slide. Likewise, it contests the notion that the presence of the knot or strands inside the tendon would increase its volume, thereby impairing the capacity to slide and the formation of collagen fibers. Moreover, areas of calcium were present in $12(33.3 \%)$ of the 36 tendons, without impairing the cylindrical shape or the texture of the tendon (Figure 12).

Six tendons (16.7\%), of which two $(5.57 \%)$ with the Brazil-2 suture, three $(8.35 \%)$ with Indiana and one $(2.78 \%)$ with Tsai, qualitatively and quantitatively demonstrated suppuration (necrosis). This was only on the periphery of the tendon and never in the center. Thus, the number of strands or the final knot(s) of the central suture did not interfere with the healing process on the tendon repair. This suppuration represented a phase of increased phagocytosis on the $15^{\text {th }}$ day due to the cut in the tendon, with the start of the inflammatory phase, or the presence of a foreign body (suture thread), and also due to granulation tissue with increased numbers of giant cells on the $30^{\text {th }}$ day (Figures 13 and 14).

With regard to the notion that the number of strands or final knots of suture threads inside the repaired tendon would impair the circulation, thereby leading to necrosis, the present investigation did not show such occurrences in any of the repair techniques (Brazil-2, Indiana and Tsai) with either four or six strands (Figure 15). 


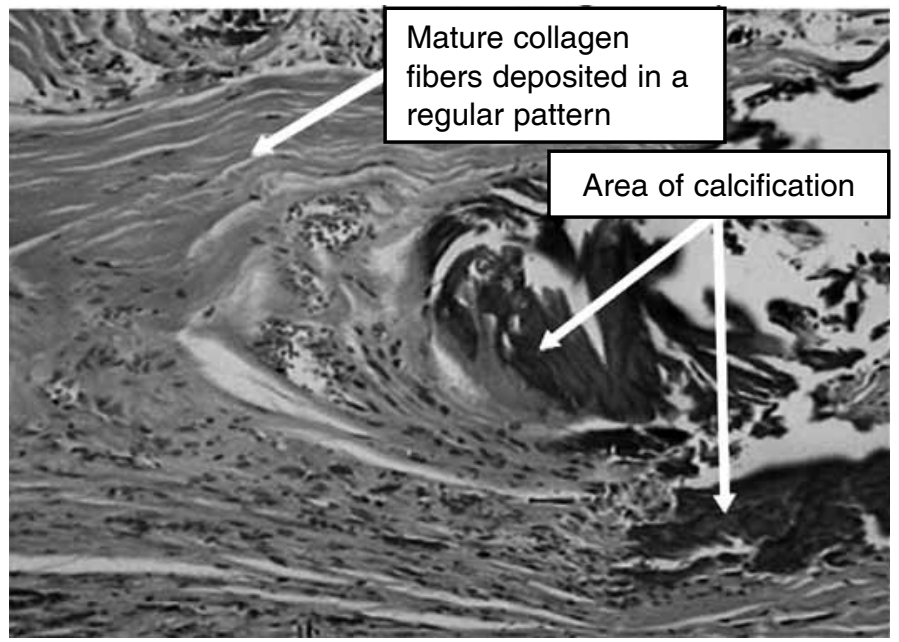

Figure 12 - Tsai technique (6-strand) on the $30^{\text {th }}$ day with areas of calcification, but with presence of well-defined healing (100x). (Source: Experimental Surgery Laboratory, Institute of Orthopedics and Traumatology, Passo Fundo, RS, Brazil).

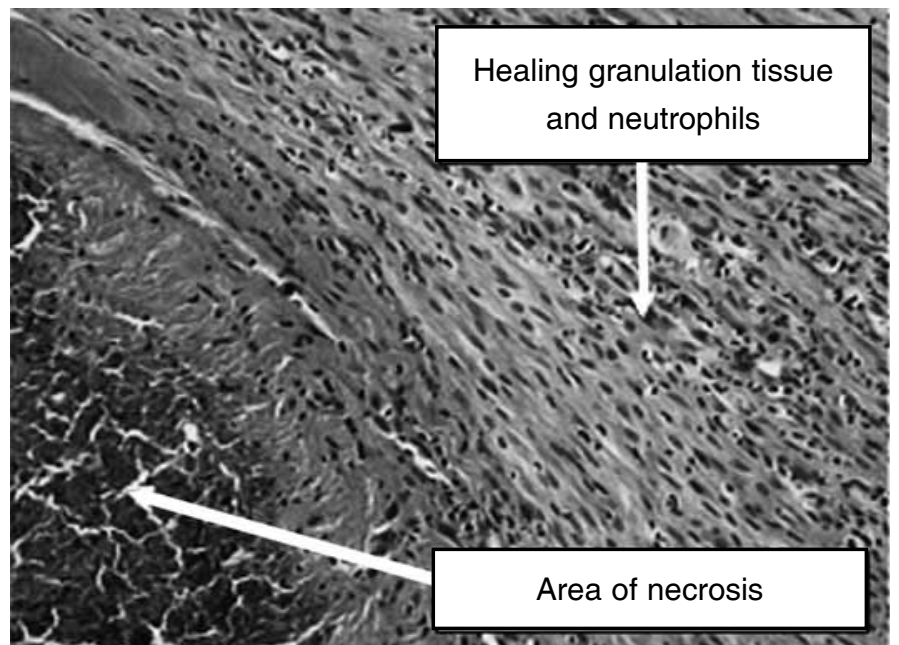

Figure 13 - Brazil technique (4-strand) on the $30^{\text {th }}$ day, showing area of necrosis on the periphery of the tendon, without impairing the healing (100x).

(Source: Experimental Surgery Laboratory, Institute of Orthopedics and Traumatology, Passo Fundo, RS, Brazil).

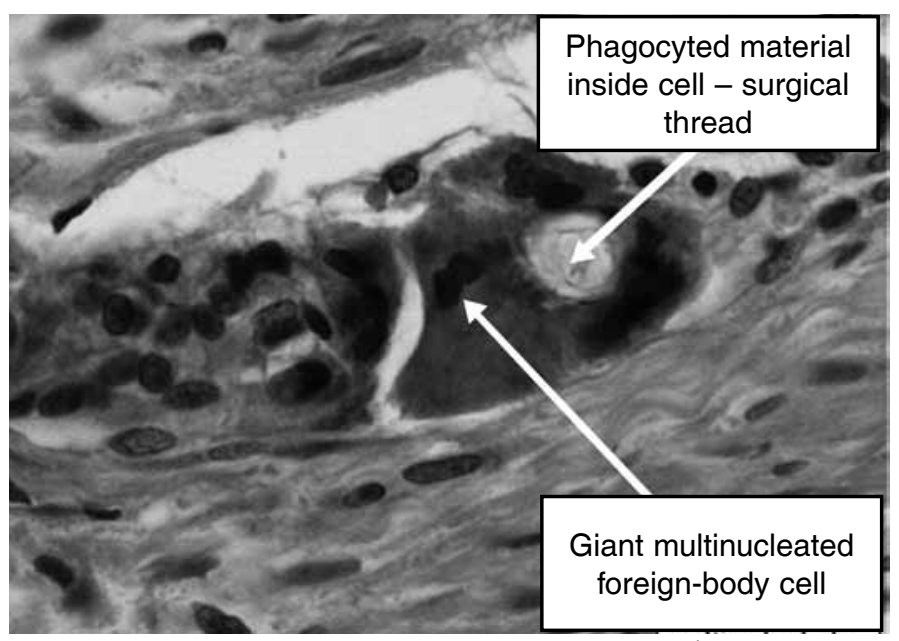

Figure 14 - Indiana technique (4-strand) on the $15^{\text {th }}$ day, showing a giant nucleated foreign-body cell (400x).

(Source: Experimental Surgery Laboratory, Institute of Orthopedics and Traumatology, Passo Fundo, RS, Brazil).

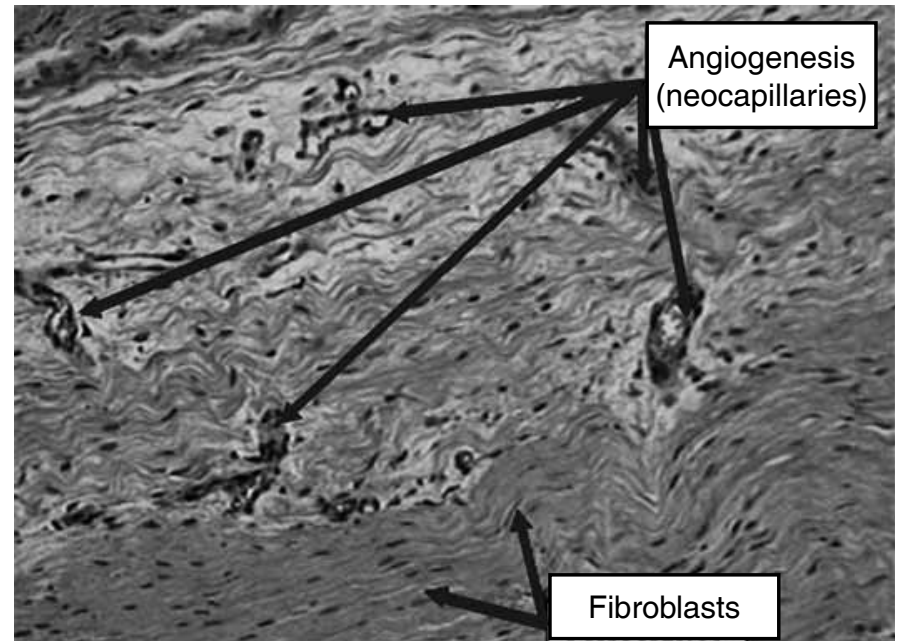

Figure 15 - Tsai technique (6-strand), showing large amount of granulation and angiogenesis on the $15^{\text {th }}$ day (100x).

(Source: Experimental Surgery Laboratory, Institute of Orthopedics and Traumatology, Passo Fundo, RS, Brazil).

\section{DISCUSSION}

According to the experiences of Elliot ${ }^{(10)}$, Strickland ${ }^{(4)}$, Kumar et $\mathrm{al}^{(26,27)}$ and $\mathrm{Tu}$ et al ${ }^{(28)}$, complete tendon healing is attained after around three months. Over this period, fibrin is recruited and forms, and is converted to solidified healed tissue, so that after this period, the hand can be released to undertake intensive activities. Early mobilization naturally does not entirely prevent adherences, but it creates a form of healing that allows the tendon to move and to return to its normal function as a mechanical piston.

Many biomechanics studies in the literature have tested repairs that were made to human hand tendon flexors and their animal equivalents, including tests on both linear and curvilinear load models. Unfortunately, the lack of uniformity between the studies has led to a wide range of results, which makes it difficult to compare these studies.

In vitro linear load testing is a stand-alone analysis method, performed outside of the tendon anatomy, which makes it possible to assess a large number of suturing methods through direct viewing. The failure (gap) between the tendon stumps or rupture is easy to measure, while ignoring the physiology of the load in relation to the environment that surrounds the tendon. This has been used in animals and in human cadavers, and can be done with a cyclical or simple linear load in order to promote rupturing of the suture.

In vitro curvilinear load testing leaves the tendon to be tested inside the intact hand. During movements made by one finger, several forces are applied to the tendon, such as dorsal and volar tension and friction within the synovial sheath. The disadvantage is that 
the tendon cannot be directly viewed, which makes it difficult to evaluate the failure (gap) measurements between the stumps or in ruptured tendon.

It is known that exercises promote synthesis and concentration, and that they influence the thickening of the collagen fibers. This has been proven in animal investigations and it increases tendon strength and stress. Although the effects from tendon exercises over prolonged periods seem to be positive, individuals may present periods of debility over the course of treatment and there may thus be a need for a resting period to achieve morphological adaptation of the tendon ${ }^{(3)}$.

In the biomechanical and histological investigation by Sardenberg ${ }^{(15)}$, Kessler (2-strand) sutures were used on the deep flexor tendon of the toes of the hind legs of 83 rabbits. The study compared the location of the final knot of the central suture: in the region of the normal vascular tendon, or in the region of the avascular fibrocartilaginous tendon. There were no differences in the biomechanical or histological characteristics of the tendon healing process.

Other studies have explained that multiple-strand sutures that are designed to bear greater pressures on the repaired tendons require more training and sophisticated skills from surgeons. Thus, the difficulty in learning these techniques discourages their use around the world, such that only $30 \%$ of surgeons use these sutures. Moreover, multiple-strand sutures may present disadvantages for untrained surgeons, such as increased volume, trauma during the repair and rupture of the vascular support for the tendon ${ }^{(6,7,11,12,29,30,31)}$. Nevertheless, this was not seen in the present investigation, but it has to be taken into account that the sutures were performed by three senior trained surgeons, for whom multiple-strand sutures were not disadvantageous in these tendons.

In the treatise on biomechanics by Boyer ${ }^{(32)}$, it was stated that the effect on tension forces from placing the suture knot inside or outside of the repaired tendon was not conclusively different. A large quantity of suture inside the tendon might increase the volume and thus decrease its capacity to slide. On the other hand, placing the suture knot outside the repaired tendon could affect the capacity to slide through worsened friction between the tendon and the synovial sheath, proximally or distally to the repair site. However, the present investigation with the four or six-strand techniques did not histologically demonstrate that placing the final knots of the central sutures inside or outside of the tendon could impair the capacity of the tendon to slide, in relation to either increased tendon volume or friction between the tendon and the synovial sheath (ANOVA; $p>0.01$ ).

In an in vivo investigation, Su et $\mathrm{a}^{(21)}$ used a tendon repair technique with a metal implant called Teno Fix (Ortheon Medical; Winter Park, Florida, United States) in the common superficial flexor tendon of the toes of the hind leg in 16 dogs. The animals were sacrificed in the $3^{\text {rd }}, 6^{\text {th }}$ and $12^{\text {th }}$ weeks after the operation. Difficulties with the plaster-cast immobilization occurred in nine of the 16 dogs, which led to rupturing of the repairs. Thus, success in the primary repairs was only achieved for seven dogs (separation $<2 \mathrm{~mm}$ ). However, it was histologically demonstrated that the repair using Teno Fix did not cause any inflammatory reaction and did not interfere with the healing. In the investigation by Wolfe et $\mathrm{al}^{(33)}$ on 30 deep flexors from cadavers, the following techniques were analyzed: (1) Cruciate, 4-strand suture; (2) Kessler, 2-strand suture; and (3) Teno Fix, metal implant. Using the Kessler repair, seven ruptures occurred out of 10 cases treated; using Cruciate, seven out of ten cases; and using Teno Fix, all cases ruptured. Thus, there was no mechanical advantage in this linear test model using cadavers. According to Coats et $\mathrm{al}^{(34)}$, although tendon repairs using Teno Fix have been shown in the laboratory to have sufficient strength, they are voluminous, there is insufficient clinical data and they are very expensive, which impedes their large-scale use. There is no doubt that it is very difficult not to have complications with plastercast immobilization, especially when dealing with irrational animals, especially rodents, as in the present study. In this regard, all the three rabbits (8.3\%) that presented abundant amorphous tissue in the histological evaluation, thus indicating a technical rupture, lost their wound protection immobilizations before completing one week. Only five rabbits reached the $15^{\text {th }}$ day with immobilization, and none of the 36 rabbits reached the $30^{\text {th }}$ day (sacrifice date) with their plastercast immobilization.

In the trial by Lawrence et $\mathrm{al}^{(31)}$, using 40 deep flexor tendons from pigs (in vitro), two techniques were used: two-strand (Kessler) and four-strand (single strands in an X shape). The techniques were performed by only two experienced surgeons (20 tendons each). The times taken to perform the two procedures were similar: a mean of 10.0 minutes for the Kessler technique and 10.1 minutes for the four-strand tech- 
nique. It was concluded that the technique with single strands in an X shape (four-strand) tolerated higher loads than shown by the Kessler technique (twostrand), with means of $52 \mathrm{~N}$ versus $29 \mathrm{~N}$, respectively, and did not require a longer time to perform it. The same observations were made in the present study in relation to the operational time for the techniques, except that the technique was performed on rabbits (in vivo), i.e. there was no additional time between the techniques, with a mean of 6.0 minutes for Tsai (six-strand), 5.7 minutes for Indiana (fourstrand) and 5.6 minutes for Brazil-2 (four-strand). The procedures were performed by three senor surgeons.

Several authors have demonstrated significant concern regarding early active mobilization in rehabilitation programs for humans. This increases the stress applied to the repaired tendon, thus resulting in formation of a significant separation (gap) at the

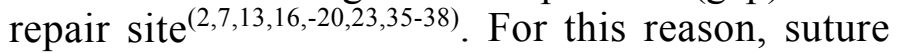
methods with four, six and eight strands are used today because of their greater resistance for bearing and maintaining tensions, thus avoiding separations of 1 and $2 \mathrm{~mm}$ and ruptures, comparatively with the two-strand methods. Nonetheless, the biomechanics are not considered to be the most important factor for avoiding ruptures. It needs to be noted that, histologically, maturation of collagen tissue is only attained at the end of the fourth month. Thus, even with suturing techniques that resist rupture, this may occur with excessive force applied before the fourth month. This is well explained in the descriptions by Gelberman et $\mathrm{al}^{(39-42)}$, Goldfarb et $\mathrm{al}^{(43)}$, Ikeda et $\mathrm{al}^{(22)}$ and $\mathrm{Wu}$ et $\mathrm{al}^{(44)}$, in which the maximum peak of fibronectin release by fibroblasts occurs from the $7^{\text {th }}$ to the $10^{\text {th }}$ day after the operation, thereby promoting the formation of new vessels (neovascularization), and this process ends between the $16^{\text {th }}$ and the $21^{\text {st }}$ day. At this point, between the first and fourth weeks, care needs to be taken to avoid re-rupture of the tendon. Thus, this is the time at which techniques using more than two strands provide greater security. By the $30^{\text {th }}$ day, the collagen fibers have become positioned in line with the longitudinal axis of the tendon. Furthermore, early mobility avoids adherences and provides thickening of the fibers, thereby strengthening the tendon. Nonetheless, it is also true to say that the increased strength during the rehabilitation does not alter the healing of the repaired tendon. This observation is proven in the present histological investigation, which showed that vessels had formed by the $15^{\text {th }}$ day and the collagen fibers had become aligned with the longitudinal axis of the tendon around the $30^{\text {th }}$ day. In other words, it cannot be forgotten that the biological time required for healing is the same for the two four, six and eight-strand techniques. In other words, the use of complete or excessive strength on the tendon needs to be delayed until the fourth month after the repair surgery.

\section{CONCLUSION}

The three different suture techniques tested with early active mobility, on flexor tendons of the hind legs (calcaneal tendons) of rabbits, i.e. two four-strand techniques (Brazil-2 and Indiana) and one six-strand technique (Tsai), presented similar behavior regarding histology, biomechanics and time taken to do the surgical repair. There was no histological difference between having the final central knot inside and outside of the repaired tendon that could impair its sliding capacity. Nor was there any difference with regard to increased tendon volume, in terms of friction between the repaired tendon and the synovial sheath. Consequently, this histological study serves to demonstrate that early active mobility affected the behavior of the collagen fibers such that they attained greater thickening, thereby providing greater strength and traction resistance to the repaired tendon.

\section{REFERENCES}

1. Wada A, Kubota H, Miyanishi K, Hatanaka H, Miura H, Iwamoto Y. Comparison of postoperative early active mobilization and immobilization in vivo utilising a four-strand flexor tendon repair. J Hand Surg Br. 2001;26(4):301-6.

2. Buendia LA, Mattar R, Ulson HJR. Estudo biomecánico comparativo da resistência à tração entre técnicas de sutura dos tendões flexores da mão. Rev Bras Ortop. 2005;40(7):407-17.

3. Goodman HJ, Choueka J. Biomechanics of the flexor tendons. Hand Clin. 2005;21(2):129-49.

4. Strickland JW. The scientific basis for advances in flexor tendon surgery. $\mathrm{J}$ Hand Ther. 2005;18(2):94-110.

5. Kuwata S, Mori R, Yotsumoto T, Uchio Y. Flexor tendon repair using the twostrand side-locking loop technique to tolerate aggressive active mobilization immediately after surgery. Clin Biomech (Bristol, Avon). 2007;22(10):1083-7.

6. Karjalainen T, He M, Chong AK, Lim AY, Ryhanen J. Nickel-titanium wire in circumferential suture of a flexor tendon repair: a comparison to polypropylene. J Hand Surg Am. 2010;35(7):1160-4.

Rev Bras Ortop. 2012;47(1):92-101 
7. Lee SK, Goldstein RY, Zingman A, Terranova C, Nasser PH, Hausman MR. The effects of core suture purchase on the biomechanical characteristics of a multistrand locking flexor tendon repair: cadaveric study. J Hand Surg Am. 2010;35:1165-71.

8. Riaz M, Hill C, Khan K, Small JO. Long term outcome of early active mobilization following flexor tendon repair in zone 2. J Hand Surg Br. 1999;24(2):157-60.

9. Strickland JW. Development of flexor tendon surgery: twenty-five years ofprogress. J Hand Surg Am. 2000;25(2):214-35.

10. Elliot D. Primary flexor tendon repair--operative repair, pulley managementand rehabilitation. J Hand Surg Br. 2002;27(6):507-13.

11. Klein L. Early active motion flexor tendon protocol using one splint. J HandTher 2003;16(3):199-206.

12. Cao Y, Tang JB. Biomechanical evaluation of a four-Strand modification of the Tang method of tendon repair. J Hand Surg Br. 2005; 30(4):374-8.

13. Tang JB. Tendon injuries across the world: treatment. Injury. 2006;37(11):1036-42

14. Kusano N, Yoshizu T, Maki Y. Experimental study of two new flexor tendon suture techniques for postoperative early active flexion exercises. J Hand SurgBr. 1999;24(2):152-6.

15. Sardenberg T. Lesão do tendão flexor: sutura na região avascular ou vascularizada? Estudo biomecânico e histológico em coelhos [tese]. Botucatu: Faculdade de Medicina de Botucatu - UNESP; 2006.

16. McLarney E, Hoffman $\mathrm{H}$, Wolfe SW. Biomechanical analysis of the cruciate four-strand flexor tendon repair. J Hand Surg Am. 1999;24(2):295-301.

17. Zatiti SC, Mazzer N, Barbieri CH. Mechanical strengths of tendon sutures. An in vitro comparative study of six techniques. J Hand Surg Br. 1998;23(2):228-33

18. Winters SC, Gelberman RH, Woo SL, Chan SS, Grewal R, Seiler JG 3rd. The effects of multiple-strand suture methods on the strength and excursion of repaired intrasynovial flexor tendons: a biomechanical study in dogs. J Hand SurgAm. 1998;23(1):97-104.

19. Shaieb MD, Singer DI. Tensile strengths of various suture techniques. J Hand Surg Br. 1997;22(6):764-7.

20. Gill RS, Lim BH, Shatford RA, Toth E, Voor MJ, Tsai TM. A comparative analysis of the six-strand double-loop flexor tendon repair and three other techniques: a human cadaveric study. J Hand Surg Am. 1999;24(6):1315-22.

21. Su BW, Raia FJ, Quitkin HM, Parisien M, Strauch RJ, Rosenwasser MP. Gross and histological analysis of healing after dog flexor tendon repair with the Teno Fix device. J Hand Surg Br. 2006;31(5):524-9.

22. Ikeda J, Zhao C, Moran SL, An KN, Amadio PC. Effects of synovial interposition on healing in a canine tendon explant culture model. J Hand Surg Am. 2010;35(7):1153-9.

23. Severo AL, Ávila AOV, Costa M, Lech OLC. Reparo em tendões flexores da mão: análise biomecânica com diferentes técnicas de sutura. Rev Bras Ortop. 2005:40(7): 418-27.

24. Strickland JW. Flexor tendon repair. Hand Clin. 1985;1(1):55-68.

25. Lim BH, Tsai T. The six - strand technique for flexor tendon repair. Atlas Hand Clin. 1996;1(1):65-75.

26. Kumar V, Abbas AK, Fausto N. Inflamação aguda e crônica. Patologia - bases patológicas das doenças. 7a. ed. São Paulo: Elsevier; 2005.

27. Kumar V, Abbas AK, Fausto N. Tecido de renovação e reparação: regeneração, cicatrização e fibrose - bases patológicas das doenças. 7a. ed. São Paulo: Elsevier; 2005. p. 91-123

28. Tu YK, On Tong G, Wu CH, Sananpanich K, Kakinoki R. Soft-tissue injury inorthopaedic trauma. Injury. 2008;39(Suppl 4):3-17.

29. Smith AM, Evans DM. Biomechanical assessment of a new type of flexor tendonrepair. J Hand Surg Br. 2001;26(3):217-9.

30. Groth GN. Current practice patterns of flexor tendon rehabilitation. J HandTher. 2005;18(2):169-74

31. Lawrence TM, Woodruff MJ, Aladin A, Davis TR. An assessment of the tensile properties and technical difficulties of two- and four-strand flexor tendonrepairs. J Hand Surg Br. 2005;30(3):294-7

32. Boyer MI. Flexor tendon biology. Hand Clin. 2005;21(2):159-66.

33. Wolfe SW, Willis AA, Campbell D, Clabeaux J, Wright TM. Biomechanic comparison of Teno fix tendon repair device with the Cruciate and modified Kessler techniques. J Hand Surg. Disponível em: www.sciencedirect.com.athenea.upo. es/sience. Acesso em 2 Março de 2007.

34. Coats RW 2nd, Echevarría-Oré JC, Mass DP. Acute flexor tendon repairs in zonell. Hand Clin. 2005;21(2):173-9.

35. Mattar RJ, Azze R, Okane SY. et al. Reconstrução dos tendones flexores com o método de Indiana. Rev Bras Ortop. 1997;32(4):310-4

36. Sanders DW, Milne AD, Dobravec A, MacDermid J, Johnson JA, King GJ. Cyclic testing of flexor tendon repairs: an in vitro biomechanical study. J Hand SurgAm. 1997;22(6):1004-10.

37. Thurman RT, Trumble TE, Hanel DP, Tencer AF, Kiser PK. Two-, four-, and six-strand zone II flexor tendon repairs: an in situ biomechanical comparison using a cadaver model. J Hand Surg Am. 1998;23(2):261-5.

38. Savage R, Pritchard MG, Thomas M, Newcombe RG. Differential splintage for flexor tendon rehabilitation: an experimental study of its effect on fingerflexion strength. J Hand Surg Br. 2005;30(2):168-74.

39. Gelberman RH, Menon J, Gonsalves M, Akeson WH. The effects of mobilization on the vascularization of healing flexor tendons in dogs. Clin Orthop Relat Res.1980;(153):283-9.

40. Gelberman RH, Amifl D, Gonsalves M, Woo S, Akeson WH. The influence of protected passive mobilization on the healing of flexor tendons: a biochemicaland microangiographic study. Hand. 1981;13(2):120-8

41. Gelberman RH, Woo SL, Amiel D, Horibe S, Lee D. Influences of flexor sheath continuity and early motion on tendon healing in dogs. J Hand Surg Am. 1990;15(1):69-77.

42. Gelberman RH, Steinberg D, Amiel D, Akeson W. Fibroblast chemotaxis aftertendon repair. J Hand Surg Am. 1991;16(4):686-93.

43. Goldfarb CA, Harwood F, Silva MJ, Gelberman RH, Amiel D, Boyer MI. The effect of variations in applied rehabilitation force on collagen concentration and maturation at the intrasynovial flexor tendon repair site. J Hand Surg Am. 2001;26(5):841-6.

44. Wu YF, Chen CH, Cao Y, Avanessian B, Wang XT, Tang JB. Molecular events of cellular apoptosis and proliferation in the early tendon healing period. $\mathrm{J}$ HandSurg Am. 2010;35(1):2-10. 